\title{
Fixation of Unstable Femoral Neck Fractures in Adults, Review Article
}

\author{
Ahmed H. Yousry ${ }^{\text {a }}$, Shady S. El-Beshry ${ }^{\text {a }}$ Gergis Nabil Benyameen ${ }^{\text {b,\# }}$ \\ ${ }^{a}$ Department of Orthopedics, ${ }^{b}$ Faculty Of Medicine, Ain Shams University, Egypt \\ Corresponding author: Gergis Nabil Benyameen; Address: Rod El Farag, Cairo. Tel.: 022458239; \\ Mob.: 01201330211; Email: dr.gergisnabil@yahoo.com
}

\begin{abstract}
Background: Femoral neck fracture is a common problem especially in young adults. There are different methods of fixation of unstable femoral neck fractures in adults, some of which are accompanied by complications.

Aim of Study: A systematic review on the different methods of fixation of unstable femoral neck fractures in adults with clarifying the incidence of nonunion, avascular necrosis, displacement and other complications in each type of fixation.

Methods: A systematic review of literature was conducted on twelve studies (556 patients) published in literature using different methods of fixation with inclusion criteria including: English literature, human studies on adults aged 18-70 years with unstable neck of femur fractures Pauwel grade 3. Exclusion criteria including: in vitro studies, pathological and nonunited fractures in people aged below 18 or above 70 years with stable neck femur fractures Pauwel grade 1,2.

Results: Targon femoral neck device had been provided to achieve highest rate of union with less complications than other methods of fixation but further evaluation of this device should be done within multiple studies in the future. Primary valgus osteotomy achieved a high union rate but still carries some complications especially delayed osteotomy site healing,coxa vara if improper reduction or fixation in addition to that it's technically demanding and needs special surgical skills.Medial buttress plate augmentation should be studied more and more in further studies with longer follow up periods and larger number of patients

Conclusion: Targon femoral neck device had been provided to achieve highest rate of union with less complications than other methods of fixation but further evaluation of this device should be done within multiple studies in the future.
\end{abstract}

Key Words: Unstable femoral neck fractures, Pauwel's III, young adults,primary valgus osteotomy.

\section{INTRODUCTION}

Femoral neck fracture is a common problem especially in young adults to the extent that more than 250000 hip fractures occur in united states each year (50\% involve the femoral neck). The number is projected to double by the year $2050^{(1)}$.

Risk factors include female sex, white race, increasing age, poor health, tobacco and alcohol use, previous fracture, fall history, and low estrogen level ${ }^{(1)}$.

Vertical shear (Pauwel type 3) femoral neck fractures result in young adult from high energy trauma extending to medial calcar and lesser trochanter and apparently evident in AP view of plain $x$ ray ${ }^{(2)}$.

A common clinical picture of femoral neck fracture patients in displaced types is non ambulatory patient on presentation with shortening and external rotation in the lower limb. Patient with non displaced or stress fracture typically lacks the deformity pattern and may be able to weight bear but the main complain becomes groin pain ${ }^{(3)}$.

An accurate history is important in patients with femoral neck fracture especially in older individuals giving history of loss of consciousness, prior syncopal episodes, medical history, chest pain, prior hip pain (pathological fracture) and pre injury ambulatory status is very important in detection the method of treatment ${ }^{(3)}$.

\section{Radiographic evaluation of femoral neck fracture depends on:}

$\mathbf{X}$ ray imaging: ${ }^{(3)} \mathrm{AP}$ view of the pelvis. AP view and cross lateral view of affected proximal femur. A physician assisted internal rotation view of the injured hip is helpful in diagnosis. Frog lateral view of the hip is contraindicated.

CT imaging: ${ }^{(4)}$ Is of value in trauma patient. Is of choice in non displaced fractures when MRI imaging is contraindicated.

\section{Pauwel classification of femoral neck fracture ${ }^{(5)}$}

This is based on the angle of fracture from horizontal (fig 1): Type $1:<30^{\circ}$. Type 2: $31-70^{\circ}$. Type 3: $>70^{\circ}$ (vertical fracture pattern).

There is also garden classification of femoral neck fracture (figure 2$)^{(4)}$. Type 1: Incomplete / valgus impacted. Type 2: Complete and non displaced on AP and lateral views. Type 3: Complete with partial displacement. Trabecular pattern of femoral head does not line up with that of acetabulum.

Type 4: Completely displaced. Trabecular pattern of the head assumes a parallel orientation with that of the acetabulum.

Aim of treatment: To minimize patient discomfort. To restore hip function. To allow rapid mobilization by early anatomic reduction and internal fixation. 


\section{PATIENTS AND METHODS}

This is a systematic review article on fixation of unstable femoral neck fractures in adults. The search will be conducted through Medline, PubMed and Cochrane library results for the following titles; Fixation of unstable femoral neck fractures in adults. Medial buttress plating for femoral neck fractures. Fixation of vertical shear fractures in femoral neck in adults.

Studies included were interventional studies, comparing results of fixation of unstable femoral neck fractures in adultst using different methods published from English literature

Inclusion criteria: 1- English language literature. 2. Human studies. 3. Article types: Clinical trial, Comparative study, Systematic reviews, Meta analysis and case series study. 4- Adults aged from 18-70 years. 5Unstable femoral neck fracture Pauwel grade III.

Exclusion criteria: 1.In vitro studies.2Fractures in people aged below 18 years or above 70 years.3-Stable femoral neck fracture Pauwel grade I, II.4-Pathological fractures.5-non united fractures.

Types of included participants: Adult patients with unstable fracture of femoral neck, medically free, with no previous hip fractures, fixations and no knee or spine problems.

\section{Different methods of fixation:}

\section{Cannulated screws:}

Cannulated screw fixation is widely accepted technique for transcervical femoral neck fracture which could be done in parallel inverted triangle configuration or recently by addition of transvere calcar srew to add stability to the fracture and to resist axial, bending, and tortional forces affecting the hip ${ }^{(6)}$.

\section{Sliding hip screw:}

Has a successful record for typical hip fractures. It is a fixed angle device so that it may provide increased resistance to varus collapse but, it lacks rotational control so, it must be mixed with anti-rotational screw to avoid rotation ${ }^{(7)}$.

\section{Dynamic condylar screw:}

Has a limited use for fixation of femoral neck fracture and alone cannot resist rotation, the same as $\mathrm{DHS}^{(6)}$.

\section{Cephalo medullary nailing:}

Fixation of the fracture of femoral neck by cephalo medullary nail is done when it is combined with femoral shaft fracture. It can resist rotation but it has the problem of catastrophic migration and violation of abductors (Z-effect) and this limits its use ${ }^{(8)}$.

\section{Medial buttress plate augmentation:}

In addition to cannulated screws, Mir and Collinge added medial buttress plate through open approach inferomedially along the fracture apex to add stability to the vertical shear fracture fixation and to perform antiglide function. This is done through smith-paterson or Watson jones approach using third tubular or minifragment plate. This overcomes shear forces and convert them into compressive forces and resist varus collapse of femoral neck ${ }^{(6)}$.

\section{Targon fixed angle femoral neck fixation implants:}

This is fixed angle device that consists of short 5-6 holes plate that incorporate three or four cancellous screws proximally in the femoral neck and two distal cortical screw collecting the dynamic compression advantage of DHS and antirotational advantage of cannulated screws ${ }^{(9)}$.

\section{Cement augmentation:}

This is performed by augmentation of the cannulated screw fixation of femoral neck fracture using polymethyl methacrylate or calcium phosphate cement. A metal catheter is introduced through the lumen of a special screw and about 1 $\mathrm{ml}$ of composite is injected under continuous fluoroscopic guidance and the injection is stopped when leakage toward the fracture or joint space, this is usually used in osteoporotic patients ${ }^{(10)}$.

\section{Primary valgus osteotomy:}

Primary valgus intertrochntric osteotomy could be done after open reduction of the fracture through modified Watson-jones approach to add stability if there is high inclination of the fracture.

Method: This is done by passing a blunt retractor at the lesser trochanter and application of closed wedge osteotomy to valgize the femur by about $20-40^{\circ}$ to decrease pauwel angle to become less than $50^{\circ}$, The osteotomy is fixed with Dynamic hip screw or $130^{\circ}$ angled blade plate. After removal of the closed wedge, then abduction of the distal femur to close the osteotomy. The patient cannot weight bear for 6 weeks then on crutches or a walker and after 10 weeks the patient can completely weight bear ${ }^{(11)}$.

The valgus osteotomy plays a two-fold role: It overcomes the shear forces and converts them to 
compression forces by placing the fracture site perpendicular to the resultant force, and buttresses the head of femur from below and improves the stability provided by the internal fixation device.

The low incidence of avascular necrosis $(8 \%)$ may be due to following factors: Osteosynthesis with valgus intertrochanteric osteotomy gives adequate, stable fixation, and the osteotomy may have a biological role in revascularization of an ischaemic femoral head ${ }^{(12)}$.

\section{Complications of femoral neck fractures:}

\section{Nonunion:}

Complicates about $5 \%$ of non displaced fracture and about $25 \%$ of displaced fracture (shear type vertical fractures).

Usually apparent after 6 months as groin pain,pain on extension, pain with weight bearing.

Treatment usually in elderly is arthroplasty but in young, patient may benefit from proximal femoral valgus osteotomy and cancellous bone graft ${ }^{(4)}$. AVN: ${ }^{(4)}$

Complicates about $10 \%$ of non displaced fracture and about $30 \%$ of displaced (shear type vertical fracture). Usually present as groin, thigh or proximal pain.

\section{Treatment is guided by symptoms:}

Early without $\mathrm{x}$ ray changes: treatment by protected weight bearing and core decompression. Late with $x$ ray changes: treatment in elderly by arthroplasty and in young individuals by valgus intertrochntric osteotomy, arthrodesis or arthroplasty.

\section{Fixation failure: ${ }^{(4)}$}

Usually in osteoporotic bone and in technical problems (malreduction and poor implant insertion.

Treatment: by repeat ORIF or prosthetic replacement.

Description of studies comparing different methods of fixation of unstable femoral neck fractures in adults:

The electronic comprehensive literature search after application of inclusion criteria identified 12 studies with total of 556 cases that were managed either by DHS, cannulated screws, fixed angle device, valgus intertrochanteric osteotomy, $130^{\circ}$ angle blade plate, Targon femoral neck system or by medial buttress plate augmentation of cannulated screws fixation.
1- Ye et al. ${ }^{(13):}$ A study containing 27 patients, with Pauwels type 3 femoral neck fracture under 60 year old operated for cannulated screws fixation and medial buttress plate augmentation. The mean age of patients was 42.1 years (range, 29-57 years). The mean follow up period was 13,6 months. The union rate was $89,3 \%$ (24 patients).Nonunion rate was $10.7 \%$ (3 patients).No patients with AVN. Femoral neck shortening occurred in two patients $(7,4 \%)$,impingement in one patient $(3,7 \%)$ and lateral femoral cutaneous nerve injury in one patient $(3,7 \%)$.

2- Schwartsmann et al. (14): A study containing 53 patients between 18-55 years, showing the results of fixation of unstable femoral neck fractures in young adults using DHS. The mean period of follow up was 2,6 years and the mean age of patients was 41,9 years. The union rate was $73,6 \%$ (39 patients). Nonunion occurred in 26,4\% (14 patients) and AVN occurred in 24,6\% (13 patients).

3- Osarumwense et al. ${ }^{(9)}$ : Twelve patients had a Targon femoral neck fixation for intracapsular displaced femoral neck fractures. With the minimum follow-up period of 24 months (range from 24 to 47 months) with a mean age of 66 years. Union rate was 91,6\% (11 patients). Nonunion rate was $8 \%$ (one patient). Avascular necrosis occurred in $8 \%$ (one patient)

4- Thein et al. ${ }^{(15)}$ : Seventy-eight patients (group 1:31,group 2:47) underwent reduction and internal fixation of displaced intracapsular femoral neck fractures with either Targon femoral neck device in group 1 or multiple cancellous $6,5 \mathrm{~mm}$ screws in group 2.The mean age was 53.7 years, and the mean follow-up period was 28.6 months. In group 1, One patient developed nonunion $(3,2 \%)$ and five patients developed AVN (16,1\%). In group 2, 22 patients developed nonunion $(46,8 \%)$ and 6 patients developed AVN (12,8\%)

5- Schwartsmann et al. (16): A study containing 96 patients, showing the results of closed reduction and internal fixation of unstable femoral neck fractures in young adults using DHS with an overall mean age of 53 years. The mean follow-up period was 64.6 months. Union rate was $81 \%$ (78 patients), AVN occurred in 20\% (19 patients) and nonunion occurred in $16 \%$ (16 patients).

6- Khoo et al. ${ }^{(17):}$ A study containing 36 patients, majority of patients with mean age of 42,1 years. All underwent urgent closed reduction and internal fixation using cannulated screws. Follow up 
period was 40 months. AVN occurred in 9 patients $(25 \%)$ and nonunion occurred in one case $(2,7 \%)$

7- Kumar et al. ${ }^{(18)}$ : A study containing 40 patients of intracapsular factures of femoral neck with mean age of 40 years, showing the results of closed reduction and internal fixation of femoral neck fractures with 3 or 4 cannulated screws, follow up period was 24 months. Union rate was $77,5 \%$ (31 patients).Nonunion occurred in $22,5 \%$ (9 patients) and AVN occurred in two patients (5\%)

8- Singh et al. ${ }^{(19):}$ A study containing 55 patients with intracapsular femoral neck fractures with mean age of 35,4 years showing results of osteosynthesis and primary valgus intertrochanteric osteotomy using broad DCP as a method of management of femoral neck fracture in adults, the mean follow up period is 4,6 years. Union rate was $92,7 \%$ (51 patients). Nonunion rate was $7,3 \%$ (4 patients), AVN rate was $11 \%$ (6 patients), shortening occurred in 6 patients $(11 \%)$, Coxa vara occurred in two patients $(3,6 \%)$, infection occurred in two patients $(3,6 \%)$ and delayed union at osteotomy site occurred in one patient $(1,8 \%)$.

9- Liporace et al. ${ }^{(20)}$ : A study containing 62 patients comparing the results of fixation of femoral neck fractures with mean age of 42 years by cannulated screws in 37 patients ( 32 patients by cannulated screws in triangular configuration and five with crossed-screw configuration) and by fixed angle device in 25 patients (14 patients by DHS, 9 patients by cephalomedullary nail and two by DCS), mean duration of follow up was 24 months. Union rate was $81 \%$ (30 patients) in those fixed with cannulated screws (37 patients), $92 \%$ (23 patients) in those fixed with fixed angle device, nonunion occurred in 10 patients (16\%):Seven patients with cannulated screws (three with crossed figure cannulated screws and four with parallel cannulated screws),one patient with DHS (septic nonunion), one patient with cephalomedullary nail and one patient with DCS. AVN occurred in 7 patients (11\%):Five patients with cannulated screws, one patient with DCS and one patient with cephalomedullary nail.

10- Gautam et al. ${ }^{(21)}$ : A study containing 25 patients aged 15-50 years old showing the results of open reduction and internal fixation by three 6,5 cancellous screws. Follow up period was 32 months. Union rate was $96 \%$ (24 patients).Nonunion occurred in One case (4\%),AVN occurred in three cases (12 percent),too long screws in three cases (12\%), superficial infection in One case (4 percent) and no patient developed deep infection.

11- Bout et al. ${ }^{(22)}$ : A study containing 40 patients showing the results of percutaneous cannulated screws fixation of displaced femoral neck fractures with the mean age of 66 years. Follow up period was 38 months. Union rate was $87.5 \%$ (35 patients).Nonunion occurred in 5 patients $(12.5 \%)$, AVN occurred in four patients (10\%). Recurrent instability and dislocation occurred in Four patients (10\%). (one of them was dislocated after one month because the inferior screw was not too close to inferior cortex leading to shortening, the other was dislocated after two weeks due to introduction of screws in the neck with no sufficient support to inferior screw and the fracture healed in malunion, the third one had no sufficient support to distal screw so, dislocation, shortening, nonunion occurred, the fourth dislocated after one week due to loss of support to distal screw by the inferior cortex)

12- Driesen et al. ${ }^{(23)}$ : A study containing 32 patients with intracapsular fractures treated with $130^{\circ}$ blade plate with minimum follow up of 30 months, with mean age of 45 years, follow up period was 45 months. Union rate was $96,87 \%$ (31 patients). Delayed union occurred in one patient (3\%), AVN occurred in two patients $(6 \%)$,wound infection occurred in two patients $(6 \%)$ and nail perforation occurred in two patients $(6 \%)$

NB: The study having the largest number. of patients was (Carlos Roberto Schwartsmann 2014) which had 96 patients and the study having smallest number of patients was Osarumwense et al. ${ }^{(9)}$ : which had 12 patients Pauwel grade 3.

\section{RESULTS}

Regarding union rate, the highest rate of union was achieved by application of Targon femoral neck device $(95,3 \%)(\mathrm{HS})$. The lowest rate of union was achieved by application of cancellous screws $(68.1 \%)(\mathrm{HS})$, the rate of union achieved by medial buttress plate augmentation $(88,9 \%)(\mathrm{HS})$ was lower than that achieved by primary valgus osteotomy $(92,7 \%)(\mathrm{HS})$, the rate of union achieved by Targon femoral neck device $(95,3 \%)$ (HS) was higher than that of fixed angle device $(83,0 \%)$ (HS) and the rate of union achieved by cancellous screws $(68,1 \%)(\mathrm{HS})$ was lower than that of cannulated screws $(80,4 \%)(\mathrm{HS})$ 
Table (1): Comparison between different methods of fixation regarding union rate.

\begin{tabular}{|c|c|c|c|c|c|c|}
\hline $\begin{array}{c}\text { Method } \\
\text { of } \\
\text { fixation }\end{array}$ & $\begin{array}{c}\text { Medial } \\
\text { buttress plate } \\
\text { augmentation }\end{array}$ & $\begin{array}{c}\text { Primary } \\
\text { valgus } \\
\text { osteotomy }\end{array}$ & $\begin{array}{c}\text { Targon } \\
\text { femoral } \\
\text { neck } \\
\text { device }\end{array}$ & $\begin{array}{c}\text { Fixed angle } \\
\text { device (DHS, } \\
\text { DCS, 130 } \mathbf{0} \text { angled } \\
\text { blade plate) }\end{array}$ & $\begin{array}{c}\text { Cancellous } \\
\text { screws }\end{array}$ & $\begin{array}{c}\text { Cannulated } \\
\text { screws }\end{array}$ \\
\hline $\begin{array}{c}\text { No of } \\
\text { patients }\end{array}$ & 27 & 55 & 43 & 206 & 72 & 153 \\
\hline $\begin{array}{c}\text { No of } \\
\text { united } \\
\text { patients }\end{array}$ & $24(88.9 \%)$ & $51(92.7 \%)$ & $41(95.3 \%)$ & $171(83.0 \%)$ & $49(68.1 \%)$ & $123(80.4 \%)$ \\
\hline X2 & 20.627 & 20.627 & 20.627 & 20.627 & 20.627 & 20.627 \\
\hline P-value & $<0.001(\mathrm{HS})$ & $\begin{array}{c}<0.001 \\
(\mathrm{HS})\end{array}$ & $\begin{array}{c}<0.001 \\
(\mathrm{HS})\end{array}$ & $<0.001(\mathrm{HS})$ & $\begin{array}{c}<0.001 \\
(\mathrm{HS})\end{array}$ & $<0.001(\mathrm{HS})$ \\
\hline
\end{tabular}

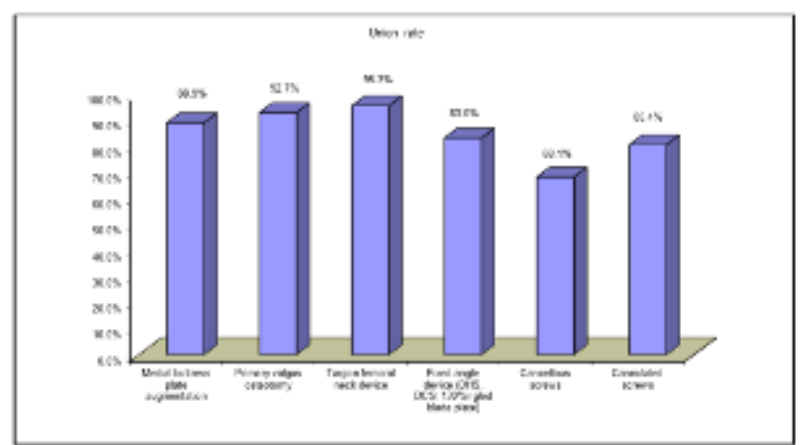

Figure (1): Comparison between different methods of fixation regarding union rate

The rate of AVN was highest with fixed angle device $(16 \%)$ (NS) and lowest with medial buttress plate augmentation $(0,0 \%)(\mathrm{NS})$. The rate of AVN with medial buttress plate augmentation $(0,0 \%)$ (NS) was lower than that of primary valgus osteotomy $(11 \%)(\mathrm{NS})$, the rate of AVN with Targon femoral neck device (14\%) was lower than that of fixed angle device (16\%)(NS) and the rate of AVN with cancellous screws $(12,5 \%)(\mathrm{NS})$ was lower than that of cannulated screws (13\%)(NS)

Table (2): Comparison between different methods of fixation regarding complications (nonunion, AVN, reoperation rates).

\begin{tabular}{|c|c|c|c|c|c|c|c|c|}
\hline & $\begin{array}{c}\text { Medial } \\
\text { buttress plate } \\
\text { augmentation }\end{array}$ & $\begin{array}{c}\text { Primary } \\
\text { valgus } \\
\text { osteotomy }\end{array}$ & $\begin{array}{c}\text { Targon } \\
\text { femoral } \\
\text { neck } \\
\text { device }\end{array}$ & $\begin{array}{c}\text { Fixed } \\
\text { angle } \\
\text { device }\end{array}$ & $\begin{array}{c}\text { Cancellous } \\
\text { screws }\end{array}$ & $\begin{array}{c}\text { Cannulated } \\
\text { screws }\end{array}$ & X2 & $\begin{array}{c}\text { P- } \\
\text { value }\end{array}$ \\
\hline $\begin{array}{c}\text { No. of } \\
\text { patients with } \\
\text { complications }\end{array}$ & 27 & 55 & 43 & 206 & 72 & 153 & & \\
\hline Nonunion & $3(11 \%)$ & $4(7.3 \%)$ & $\begin{array}{c}2 \\
(4.7 \%)\end{array}$ & $\begin{array}{c}37 \\
(18 \%)\end{array}$ & $23(32 \%)$ & $21(13.7 \%)$ & 22.291 & $\begin{array}{c}0.001 \\
(\mathrm{HS})\end{array}$ \\
\hline AVN & $0(0.0 \%)$ & $6(11 \%)$ & $6(14 \%)$ & $\begin{array}{c}33 \\
(16 \%)\end{array}$ & $9(12.5 \%)$ & $20(13 \%)$ & 5.795 & $\begin{array}{c}0.327 \\
(\mathrm{NS})\end{array}$ \\
\hline Reoperation & $0(0.0 \%)$ & $6(11 \%)$ & $\begin{array}{c}8 \\
(18.6 \%)\end{array}$ & $\begin{array}{c}66 \\
(32 \%)\end{array}$ & $15(21 \%)$ & $32(21 \%)$ & 23.248 & $\begin{array}{c}0.000 \\
(\mathrm{HS})\end{array}$ \\
\hline
\end{tabular}

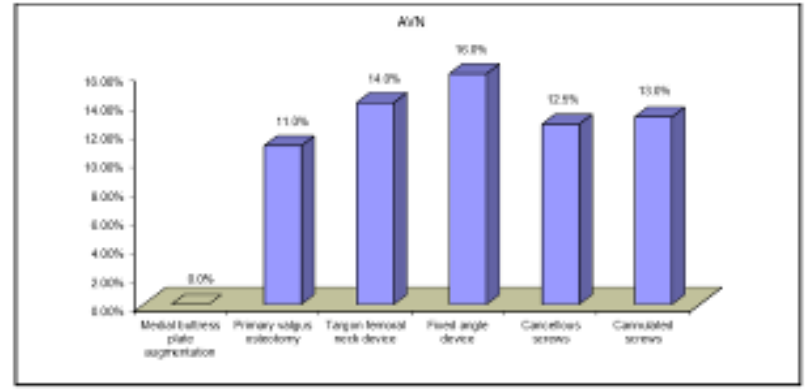

Figure (2): Comparison between different methods of fixation regarding AVN

The rate of reoperation was highest with fixed angle device $(32 \%)(\mathrm{HS})$ and lowest with medial buttress plate augmentation $(0,0 \%)(\mathrm{HS})$. The rate of reoperation with medial buttress plate augmentation $(0,0 \%)(\mathrm{HS})$ was lower than that of primary valgus osteotomy $(11 \%)(\mathrm{HS})$. The reoperation rate with Targon femoral neck device $(18,6 \%)(\mathrm{HS})$ was lower than that of fixed angle device $(32 \%)(\mathrm{HS})$ and reoperation rate with both cancellous screws and cannulated screws fixation was $21 \%$ (HS)

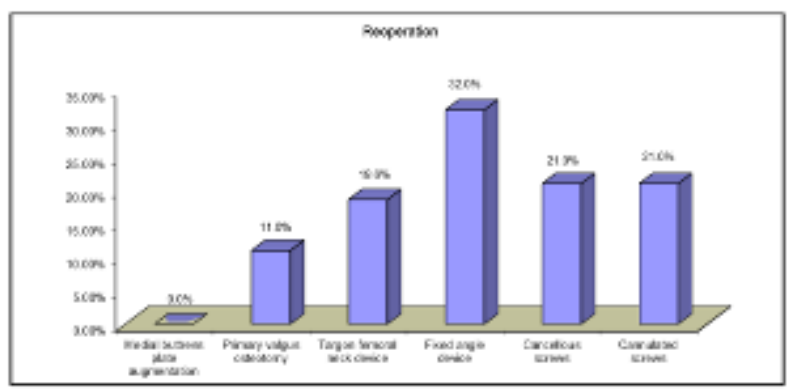

Figure (3): Comparison between different methods of fixation regarding reoperation rate.

Regarding fixed angle devices, $130^{\circ}$ double angled blade plate achieved highest union rate $(96,6 \%)$ (NS) while DCS achieved lowest union rate $(50,0 \%)(\mathrm{NS})$. The rate of union achieved by Dynamic hip screw $(79,8 \%)(\mathrm{NS})$ was lower than that of $130^{\circ}$ double angled blade plate $(96,9 \%)(\mathrm{NS})$ and rate of union achieved by DCS (50\%)(NS) was lower than that of cephalomedullary nail $(88,9 \%)$ (NS).

Table (3): Comparison between different methods of fixed angle device regarding union rate.

\begin{tabular}{|c|c|c|c|c|}
\hline \multirow{2}{*}{$\begin{array}{c}\text { No of patients } \\
\text { fixed with } \\
\text { fixed angle } \\
\text { device } \\
\end{array}$} & $\begin{array}{c}\text { Dynamic } \\
\text { hip screw }\end{array}$ & $\begin{array}{c}1^{130^{\circ}} \text { double } \\
\text { angle blade } \\
\text { plate }\end{array}$ & DCS & $\begin{array}{c}\text { Cephallomedullary } \\
\text { nail }\end{array}$ \\
\hline & 163 & 32 & 2 & 9 \\
\hline \begin{tabular}{|c|}
$\begin{array}{c}\text { No of united } \\
\text { patients }\end{array}$ \\
\end{tabular} & $130(79.8 \%)$ & $31(96.9 \%)$ & $1(50.0 \%)$ & $8(88.9 \%)$ \\
\hline $\mathrm{X} 2$ & 7.156 & 7.156 & 7.156 & 7.156 \\
\hline P-value & 0.067 (NS) & 0.067 (NS) & 0.067 (NS) & 0.067 (NS) \\
\hline
\end{tabular}




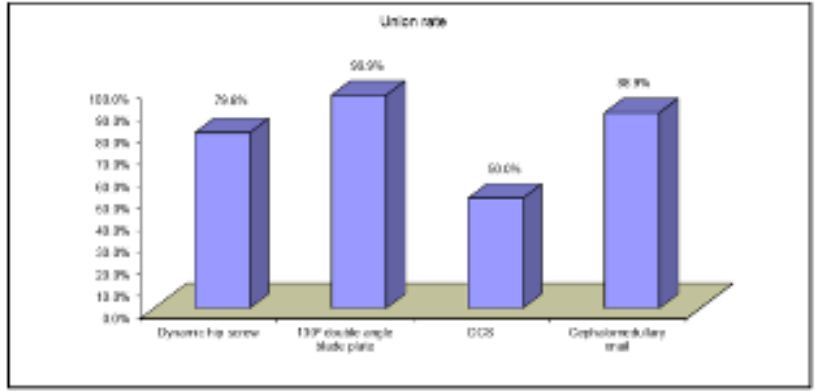

Figure (4): Comparison between different methods of fixed angle device regarding union rate.

Regarding fixed angle devices, the highest rate of AVN was with Dynamic hip screw $(18,4 \%)(\mathrm{NS})$ and lowest with DCS $(0,0 \%)(\mathrm{NS})$. The rate of AVN with DHS $(18,4 \%)$ (NS) was higher than that of $130^{\circ}$ double angled blade plate $(6,3 \%)(\mathrm{NS})$ and rate of AVN with DCS $(0,0 \%)(\mathrm{NS})$ was lower than that of cephalomedullary nail $(11,1 \%)(\mathrm{NS})$

Table (4): Comparison between different fixed angle devices regarding complications.
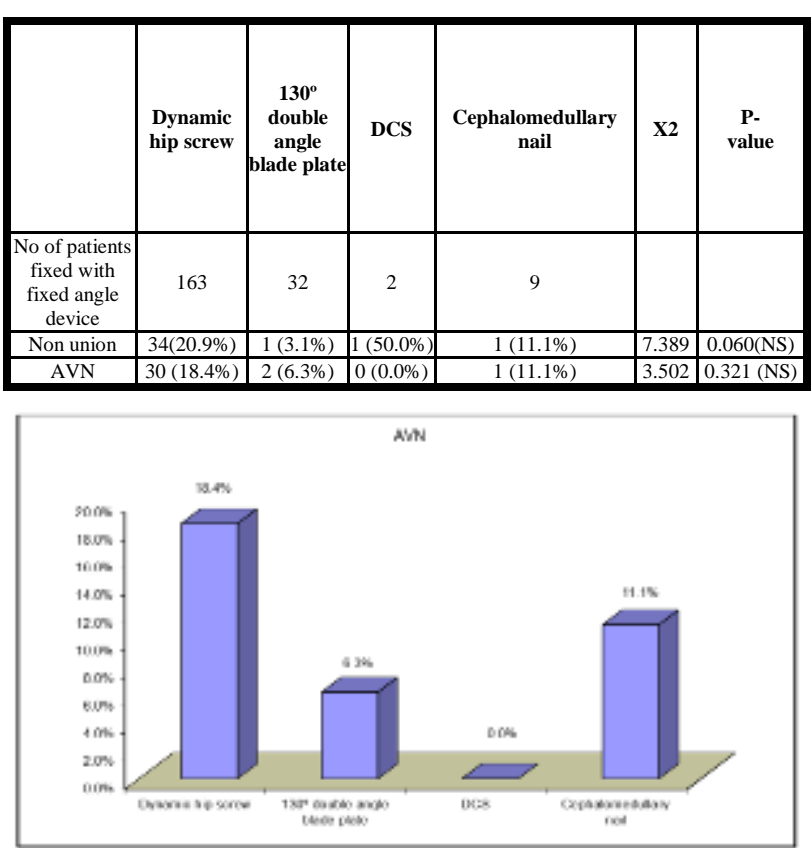

Figure (5): Comparison between different fixed angle devices regarding AVN.

Regarding cancellous screws fixation, open reduction achieved higher union rate than closed reduction. Rate of nonunion with open reduction $(4 \%)(\mathrm{HS})$ was lower than that of closed reduction $(46,8 \%)(\mathrm{HS})$.rate of AVN with open reduction $(12 \%)$ was slightly lower than that of closed reduction $(12,8 \%)(\mathrm{NS})$ and reoperation rate with open reduction $(4 \%)(\mathrm{S})$ was lower than that of closed reduction $(29,8 \%)(\mathrm{S})$

Table (5): Comparison between open and closed reduction with cancellous screws.

\begin{tabular}{|l|c|c|c|c|}
\hline \multirow{2}{*}{$\begin{array}{c}\text { No of } \\
\text { patients }\end{array}$} & $\begin{array}{c}\text { Open } \\
\text { reduction }\end{array}$ & $\begin{array}{c}\text { Closed } \\
\text { reduction }\end{array}$ & \multicolumn{2}{c|}{ Chi-square test } \\
\cline { 2 - 5 } & No. $=\mathbf{2 5}$ & No. $=\mathbf{4 7}$ & $\mathbf{X 2}$ & P-value \\
\hline Non union & $1(4.0 \%)$ & $22(46.8 \%)$ & 13.756 & $0.000(\mathrm{HS})$ \\
\hline AVN & $3(12.0 \%)$ & $6(12.8 \%)$ & 0.009 & $0.924(\mathrm{NS})$ \\
\hline $\begin{array}{l}\text { Reoperation } \\
\text { rate }\end{array}$ & $1(4.0 \%)$ & $14(29.8 \%)$ & 6.58 & $0.010(\mathrm{~S})$ \\
\hline
\end{tabular}

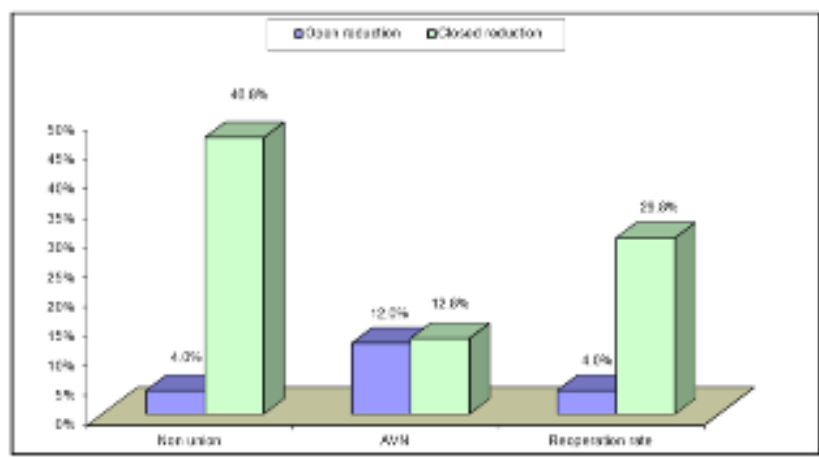

Figure (6): Comparison between open and closed reduction with cancellous screws.

\section{DISCUSSION}

Despite the breakthrough in medicine, femoral neck fracture in adults is still common and complicated problem with increasing rates nowadays. Multiple treatment modalities had been used for the femoral neck fractures by direct fixation, augmentation or valgus intertrochanteric osteotomy. The main goal of the management is to increase quality of life of the affected patient ${ }^{(1)}$.

The aim of the study was to compare medial buttress plate augmentation of cannulated screws fixation to Targon femoral neck device, primary valgus intertrochanteric osteotomy and other traditional methods of management e.g., cannulated screws, DHS, DCS. Cephalomedullary nailing regarding union rate, nonunion rate, AVN rate and reoperation rate to realize the most beneficial method in management.

Our search strategy identified twelve articles out of twenty based on our inclusion and exclusion criteria providing the needed tools for accurate comparison between different tools regarding mean age of patients in each study, follow up period, rate of union, rate of nonunion, rate of AVN and reoperation rate. 
The mean age of patients was highest with Targon femoral neck device application and lowest with primary valgus osteotomy (HS). The mean age of patients with medial buttress plate augmentation was higher than that of primary valgus osteotomy, the mean age of patients with Targon femoral neck device was higher than that of fixed angle device and the mean age of patients with cancellous screws was lower than that of cannulated screws (HS) ${ }^{(9,12,13,15,19)}$.

The follow up period was highest with primary valgus osteotomy and lowest with medial buttress plate augmentation of cannulated screws (HS).the mean follow up period with medial buttress plate augmentation was lower than that of primary valgus osteotomy (HS), the mean follow up period with Targon femoral neck device was lower than that of fixed angle device (HS) and the mean follow up period with cancellous screws was lower than that of cannulated screws (HS) ${ }^{(13,19)}$.

Regarding union rate, the highest rate of union was achieved by application of Targon femoral neck device (HS).The lowest rate of union was achieved by application of cancellous screws (HS), the rate of union achieved by medial buttress plate augmentation was lower than that achieved by primary valgus osteotomy(HS), the rate of union achieved by Targon femoral neck device was higher than that of fixed angle device (HS) and the rate of union achieved by cancellous screws was lower than that of cannulated screws (HS) ${ }^{(13,15)}$.

The rate of AVN was highest with fixed angle device and lowest with medial buttress plate augmentation $(0,0 \%)(\mathrm{NS})$. The rate of AVN with medial buttress plate augmentation was lower than that of primary valgus osteotomy (NS), the rate of AVN with Targon femoral neck device was lower than that of fixed angle device (NS) and the rate of AVN with cancellous screws was lower than that of cannulated screws (NS) ${ }^{(13,14,16)}$.

The rate of reoperation was highest with fixed angle device (HS) and lowest with medial buttress plate augmentation $(0,0 \%)$ (HS).The rate of reoperation with medial buttress plate augmentation was lower than that of primary valgus osteotomy (HS).The reoperation rate with targon femoral neck device was lower than that of fixed angle device (HS) and reoperation rate with both cancellous screws and cannulated screws fixation was equal (HS) ${ }^{(13,14)}$.

Impingement, lateral femoral cutaneous nerve injury are special complications of medial buttress plating but are rare. Delayed osteotomy site healing is a special and rare complication associated with primary valgus osteotomy ${ }^{(13)}$.

Regarding fixed angle devices, $130^{\circ}$ double angled blade plate achieved highest union rate (NS) while DCS achieved lowest union rate (NS).The rate of union achieved by Dynamic hip screw was lower than that of $130^{\circ}$ double angled blade plate (NS) and rate of union achieved by DCS was lower than that of cephalomedullary nail (NS) ${ }^{(16,20,23)}$.

Regarding complications associated with fixed angle devices, nonunion rate was highest with DCS (NS) and lowest with $130^{\circ}$ double angled blade plate (NS), the rate of nonunion associated with Dynamic hip screw was higher than that of $130^{\circ}$ double angled blade plate (NS) and the rate of nonunion with DCS was higher than that of cephalomedullary nail(NS) ${ }^{(14,20)}$.

Regarding fixed angle devices, the highest rate of AVN was with Dynamic hip screw (NS) and lowest with DCS $(0,0 \%)(\mathrm{NS})$. The rate of AVN with DHS was higher than that of $130^{\circ}$ double angled blade plate (NS) and rate of AVN with DCS was lower than that of cephalomedullary nail (NS) ${ }^{(16,20)}$.

Regarding cancellous screws fixation, open reduction achieved higher union rate than closed reduction. Rate of nonunion with open reduction (HS) was lower than that of closed reduction (HS). Rate of AVN with open reduction was slightly lower than that of closed reduction (NS) and reoperation rate with open reduction (S) was lower than that of closed reduction $(\mathrm{S})^{(15,21)}$.

\section{CONCLUSION}

Femoral neck fracture in adults is still a common and complicated problem with increasing rates nowadays. Multiple treatment modalities had been used for the femoral neck fractures by direct fixation, augmentation or valgus intertrochanteric osteotomy. The main goal of the management is to increase quality of life of the affected patient.

Several methods had been searched in this study e.g. Medial buttress plate augmentation, Targon femoral neck device, primary valgus osteotomy, fixed angle devices, cancellous screws and cannulated screws.

Targon femoral neck device had been provided to achieve highest rate of union with less complications than other methods of fixation but further evaluation of this device should be done within multiple studies in the future. 
Primary valgus osteotomy achieved a high union rate but still carries some complications especially delayed osteotomy site healing, coxa vara if improper reduction or fixation in addition to that it's technically demanding and needs special surgical skills. Medial buttress plate augmentation should be studied more and more in further studies with longer follow up periods and larger number of patients.

Open reduction is preferred on closed reduction of femoral neck fracture to add good visualization of the fracture and to allow proper evacuation of the fracture hematoma which affects blood supply of femoral head.

Further studies should be performed on other methods of fixation of femoral neck fractures in adults on larger number of patients and with larger follow up periods.

\section{Recommendations}

It's recommended to use Targon femoral neck device in management of femoral neck fracture because it is better than other methods with lower complication rate than other methods. In the future, other studies should be performed on medial buttress plate augmentation of femoral neck fixation with larger number of patients and longer follow up periods and prospective studies should be done to compare between different methods of fixation with larger number of patients and longer follow up periods.

\section{REFERENCES}

1. Gray AJ, Parker MJ (1994): Intracapsular fractures of the femoral neck in young patients. Injury, 25(10):667-669.

2. 2. Weil YA, Khoury A, Zuaiter I, Safran O, Liebergall M, Mosheiff R (2012): Femoral Neck Shortening and Varus Collapse After Navigated Fixation of Intracapsular Femoral Neck Fractures. J Orthop Trauma, 26(1):19-23.

3. 3. Koval Z (1994): Hip Fractures: I. Overview and Evaluation and Treatment of FemoralNeck Fractures. J Am Acad Orthop Surg., 2(3):141-149.

4. Collinge CA, Mir H, Reddix R (2014): Fracture Morphology of High Shear Angle "Vertical" Femoral Neck Fractures in Young Adult Patients. J Orthop Trauma, 28(5):270-275.
5. Pauwels F (1935): Der Schenkelhalsbruch, Ein Mechanisches Problem: Grundlagen Des Heilungsvorganges, Prognose Und Kausale Therapie. Stuttgart: Ferdinand Enke Verlag. www.worldcat.org/.../schenkelhalsbruch-einmechanisches-problem

6. Mir H, Collinge C (2015): Application of a medial buttress plate may prevent many treatment failures seen after fixation of vertical femoral neck fractures in young adults. Med Hypotheses, 84(5):429-433.

7. Baitner AC, Maurer SG, Hickey DG et al. (1999): Vertical shear fractures of the femoral neck. A biomechanical study. Clin Orthop Relat Res., (367):300-305.

8. Mir HR, Edwards $P$, Sanders $R$, Haidukewych G (2011): Results of Cephallomedullary Nail Fixation for Displaced Intracapsular Femoral Neck Fractures. J Orthop Trauma, 25(12):714-720.

9. Osarumwense $D$, Tissingh $E$, Wartenberg $K$ et al. (2015): The Targon FN system for the management of intracapsular neck of femur fractures: minimum 2-year experience and outcome in an independent hospital. Clin Orthop Surg., 7(1):22-28.

10. Frihagen F, Madsen JE, Reinholt FP, Nordsletten L (2007): Screw augmentation in displaced femoral neck fractures. Injury, 38(7):797-805.

11. Gupta S, Kukreja S, Singh V (2014): Valgus Osteotomy and Repositioning and Fixation with a Dynamic Hip Screw and a $135^{\circ}$ SingleAngled Barrel Plate for Un-United and Neglected Femoral Neck Fractures. J Orthop Surg., 22(1):13-17.

12. Magu NK, Singh R, Mittal R, Garg R, Wokhlu A, Sharma AK (1992): Osteosynthesis and primary valgus intertrochanteric osteotomy in displaced intracapsular fracture neck of femur with osteoporosis in adults. Injury, 36(1):110-122

13. Ye Y, Chen K, Tian K, Li W, Mauffrey C, Hak DJ (2017): Medial buttress plate augmentation of cannulated screw fixation in vertically unstable femoral neck fractures: Surgical technique and preliminary results. Injury, 48(10):2189-2193. 
14. Schwartsmann CR, Lammerhirt HM, Spinelli L, Ungaretti Neto A (2017): Treatment of displaced femoral neck fractures in young patients with DHS and its association to osteonecrosis. Rev Bras Ortop., Rev Bras Ortop.,53(1)82-87.

15. Thein R, Herman A, Kedem $P$, Chechik A, Shazar N (2014): Osteosynthesis of Unstable Intracapsular Femoral Neck Fracture by Dynamic Locking Plate or Screw Fixation. J Orthop Trauma, 28(2):70-76.

16. Schwartsmann CR, Jacobus LS, Spinelli L de F et al. (2014): Dynamic hip screw for the treatment of femoral neck fractures: a prospective study with 96 patients. ISRN Orthop., 257871.

17. Khoo C, Haseeb A, Ajit Singh V (2014): Cannulated Screw Fixation For Femoral Neck Fractures: A 5-year Experience In A Single Institution. Malaysian Orthop J.,8(2):14-21.

18. Kumar S, Bagchi Citation Kumar DS, Bagchi D (2009): Fractures Of The Neck Of The FemurTreated With Multiple Cannulated Screws In Younger Patients -A Study Of 40 Cases. Internet J Orthop Surg., ispub.com/IJOS/18/1/7018.
19. Singh MP, Aggarwal AN, Arora A, Dhammi IK, Singh J (2008): Unstable recent intracapsular femoral neck fractures in young adults: osteosynthesis and primary valgus osteotomy using broad dynamic compression plate. Indian J Orthop., 42(1):43-48.

20. Liporace F, Gaines $\mathbf{R}$, Collinge $C$, Haidukewych GJ (2008): Results of Internal Fixation of Pauwels Type-3 Vertical Femoral Neck Fractures. J Bone Jt Surgery-American, 90(8):1654-1659.

21. Gautam VK, Anand S, Dhaon BK (1998): Management of displaced femoral neck fractures in young adults (a group at risk). Injury,29(3):215-218.

22. Bout CA, Cannegieter DM, Juttmann JW (1997): Percutaneous cannulated screw fixation of femoral neck fractures: the three point principle. Injury,28(2):135-139.

23. Driesen R, Nijs S, Broos PL, Fabry G (1994): Unstable femoral neck fractures treated with a 130 degrees blade plate. Acta Orthop Belg.,60(3):322-327. 